\title{
Os estudos sociais da ciência e tecnologia na contemporaneidade
}

PREMEBIDA, Adriano; NEVES, Fabrício; DUARTE, Tiago (Orgs.). Investigações contemporâneas em estudos sociais da ciência e tecnologia. Jundiaí: Paco Editorial, 2015.

\section{Everton Garcia da Costa*}

$\Lambda$ compreensão de ciência apresentada por Thomas Kuhn (1996) em sua obra basilar A estrutura das revoluções científicas, publicada em 1962, causou um frenesi generalizado na filosofia da ciência. Até bem pouco tempo antes, ainda perdurava a crença de que o rigor metodológico garantiria à prática científica imunidade frente a fatores de ordem externa. Por esse viés, a ciência era vista como um sistema fechado, que visava ao progresso social e à paz universal. Do mesmo modo, o pesquisador, isto é, o cientista era visto como um verdadeiro "herói do saber", na luta por um bom fim ético-político (Lyotard, 1986). Os quatro imperativos do ethos científico propostos por Robert Merton (1970) na década de 1940 mostram que essa visão "romantizada" da ciência sobreviveu até meados do século XX. Todavia, a publicação do pensamento de Kuhn abalou profundamente essa crença. Kuhn defendeu que fatores políticos, históricos, psicológicos e sociais são intrínsecos à prática científica. Ao voltar-se para a história da ciência, o pensador estadunidense apresentou uma série de exemplos concretos que sustentavam sua tese e que deram uma guinada nas análises sociais da atividade científica.

Assim, desde sua publicação, há cerca de 50 anos, o pensamento kuhniano acendeu o estopim para a proliferação de diferentes análises sociais da ciência, no âmbito dos estudos sociais da ciência e tecnologia. O livro Investigações contemporâneas em estudos sociais da ciência e tecnologia - organizado por Adriano Premebida (FDB), Fabrício Monteiro Neves (UnB) e Tiago Ribeiro Duarte (UnB) - reúne justamente uma rica série de textos que apresentam um panorama do estágio atual dos estudos sociais da ciência e tecnologia. A seguir, são apresentados brevemente cada um dos capítulos que compõem a coletânea.

Na "Introdução", o sociólogo britânico Harry Collins (Cardiff University) - um dos fundadores da área -, apresenta um breve panorama histórico dos estudos sociais
Recebido: 24.10 .17 Aprovado: 25.01 .18

\footnotetext{
* Everton Garcia da Costa é doutor em sociologia pela Universidade Federal do Rio Grande do Sul (UFRGS), Porto Alegre, Rio Grande do Sul, Brasil; licenciado em letras e mestre em ciências sociais pela Universidade Federal de Pelotas (UFPel). Orcid: 0000-00024446-2173. <eve.garcia.costa@ gmail.com>.
} 
da ciência e tecnologia. Collins argumenta que a história dos estudos sociológicos da ciência pode ser dividida em três ondas.

i. A primeira onda se refere à época de Merton e de filósofos como Karl Popper. Os pensadores desse período - segundo Collins - acreditavam que o conhecimento científico consistia em um saber superior, e que o tipo de ordem social mais adequado para o desenvolvimento da ciência era a democracia.

ii. A segunda onda teve início na década de 1970, tendo sido influenciada, sobretudo, pelo pensamento de Kuhn e pela filosofia do segundo Wittgenstein. "O problema apresentado nesse período é entender o valor da ciência" ao mesmo tempo em que se sabe que ela "não possui nenhuma justificação epistemológica especial" (p. 19). Assim, por um lado, a segunda onda nivelou a ciência epistemologicamente junto aos demais saberes, desconstruindo a visão ingênua que dela se tinha e que fora mantida pela primeira onda. Por outro lado, ela trouxe à luz um importante conjunto de questões: é praticamente impossível pensar um mundo super-habitado como o nosso, no qual não exista a ciência.

iii. A terceira onda tem justamente o objetivo de superar esse problema. Ela reconhece que a ciência não goza de nenhum prestígio epistemológico, todavia, defende que "as opiniões daqueles que 'sabem o que estão falando' valem mais do que as daqueles que não sabem" (p. 20). Em outras palavras, Collins defende que a terceira onda dos estudos sociais da ciência e tecnologia deve partir do princípio da expertise, ou seja, da crença de que uma decisão tomada por um expert provavelmente será a mais adequada - mesmo sabendo-se que os experts nem sempre estarão certos e que, em algum momento, cometerão erros.

O capítulo 1 - "Apontamentos sobre Thomas Kuhn e Paul Feyerabend: antagonismo, aproximações e os estudos sociais da ciência" -, é de autoria de Luiz Abrahão (Cefet/MG), que toma como objeto de análise algumas das principais obras de Kuhn e Feyerabend - intelectuais normalmente descritos como os principais inspiradores dos estudos sociais da ciência e tecnologia contemporâneos. Além disso, são analisadas também a correspondência enviada por Feyerabend a Kuhn, cartas escritas na época em que ambos conviveram na Universidade de Berkeley. Desse modo, Abrahão desenvolve um texto que aponta semelhanças e diferenças entre os pensamentos kuhniano e feyerabendiano. No que concerne às diferenças entre esses dois pensadores, Abrahão ressalta três objeções de Feyerabend a Kuhn: 
i. o filósofo austríaco rebate a ideia kuhniana de paradigma, contra-argumentando que a física moderna, por exemplo, desenvolveu-se sem a existência de um paradigma dominante;

ii. para Feyerabend, o argumento kuhniano de que o progresso científico é garantido pela "ciência normal" constitui um conteúdo dogmático danoso às análises sociais da ciência; e, por fim,

iii. Feyerabend afirma que Kuhn oscila entre uma abordagem descritiva e uma prescritiva normativa.

Apesar dessas objeções, Abrahão destaca que Kuhn e Feyerabend aproximam-se ao final de suas carreiras, sobretudo através da crítica que ambos elaboram em direção ao "desconstrutivismo" do Programa Forte de Sociologia e das abordagens radicais de David Bloor.

O capítulo 2, intitulado "A sociologia do conhecimento de E. Durkheim e o Programa Forte" é assinado por Tiago Duarte. Em seu texto, Duarte elabora um estudo comparativo entre Durkheim - que, segundo o autor, pode ser considerado o precursor das investigações sociológicas do conhecimento - e o Programa Forte de Sociologia. De forma mais precisa, o texto busca "evidenciar o projeto da Sociologia Forte e estender as considerações durkheimianas a respeito da ciência" (p. 61). Além disso, o autor tem o intuito de rebater uma crítica lançada tanto por Kuhn como por Latour em direção ao Programa Forte. Segundo esta crítica, a Sociologia Forte não atribui nenhum papel à realidade empírica na determinação das teorias científicas. Segundo Duarte, esse argumento é infundado. O Programa Forte reconhece a existência de uma realidade material independente e exterior aos seres humanos, sobre a qual o conhecimento é formulado. Reconhece também que os indivíduos possuem um aparato sensorial capaz perceber tal realidade. Todavia, o programa parte do princípio de que "diferentes pessoas, expostas a um mesmo fenômeno empírico, formulam ideias distintas sobre o que viram" (p. 78).

Na sequência, somos apresentados ao capítulo 3 intitulado "Os impasses conceituais de Latour: o humano, o social e a simetria", de Carlos Alvarez Maia (Uerj). O texto apresenta uma crítica ao pensamento de Latour, mais precisamente aos conceitos de "humano", "social" e "simetria" desenvolvidos pelo sociólogo e antropólogo francês. Segundo Maia, para escapar do relativismo causado pela dicotomia material/simbólico, Latour desenvolve o conceito de simetria, todavia, ao invés de resolver o problema, essa noção causa um verdadeiro "imbróglio compreensivo" (p. 87). Assim, ao visar à superação das dicotomias natureza/sociedade, material/ 
1. Segundo os autores, "expert é todo indivíduo que possui a capacidade de agir e falar legitimamente em um determinado espaço da vida social, como a ciência, sobre temas restritos a este espaço" (p. 119). simbólico, bem como os impasses conceituais sobre os quais esbarra a teoria de Latour, Maia elabora uma reflexão "sobre o que é o humano tal que seja possível compreender a distinção entre humanos e coisas" (p. 87). Para desenvolver sua argumentação, o autor mobiliza algumas das ideias de Karen Knorr-Cetina, sobretudo a noção de "pós-social", a qual busca sintetizar o simbólico e o material.

O capítulo 4 - "A dinâmica da expertise no Juicio Ciudadano no Uruguai: cidadania, poder e energia nuclear" - é assinado por Fabrício Neves (UnB), Vinícius Pinto (UFSC) e Julio Salon (UFRGS). Os autores apresentam o resultado de uma pesquisa realizada no ano de 2011, sobre as conferências de Juicio Ciudadano, realizadas pela Universidad de la República, no Uruguai. Tais conferências visavam criar um espaço de deliberação para que um grupo de cidadãos não experts ${ }^{1}$ pudesse emitir sua opinião sobre temas selecionados relacionados à ciência e tecnologia, como a energia nuclear, por exemplo, tema da primeira conferência. Segundo os autores, como o Juicio trata de um evento bastante recente, não se sabe ainda sua real eficácia como alternativa de participação cidadã. Apesar disso, os autores apontam dois aspectos relativos à experiência vivenciada junto ao evento.

i. Primeiro, destacam que os cidadãos não experts tiveram acesso ao material relativo aos temas do evento meses antes de sua realização, de modo que apresentaram um incremento de expertise que os habilitou a interagir com os experts. No entanto, os autores ressaltam que não encontraram evidências de que esse incremento de expertise "possa deixar o nível meramente interacional para chegar a um nível contributivo" (p. 135).

ii. O segundo aspecto destacado pelos autores é o de que a realização do Juicio Ciudadano, em virtude de sua flexibilidade e abertura à prática interacional e ao engajamento espontâneo, cria uma nova forma participação em ciência e tecnologia.

O Capítulo 5 - "O papel das aproximações na física: o caso de experimentos e teorias controversas no efeito Casimir" -, escrito por Luis Reyes-Galindo (Cardiff University), traz uma reflexão em torno da física teórica e da ideia de aproximação. Segundo o autor, uma aproximação "implica uma solução que se sabe próxima à resolução exata de um problema, tendo consciência de que o resultado aproximado é distinto da solução exata" (p. 139). Reyes-Galindo destaca que a física teórica tem utilizado as aproximações para resolver a maior parte dos enigmas com os quais tem se deparado, uma vez que é impossível atribuir à maioria desses enigmas uma resposta exata. Nesse sentido, o autor apresenta três tipos distintos de aproximação: 
i. aproximações utilizadas para explicar fenômenos novos, atípicos, ou que não podem ser solucionados pela prática de laboratório;

ii. aproximações utilizadas na explicação de fenômenos ou na criação de modelos por meio de teorias inadequadas, incorretas ou ultrapassadas; e

iii. aproximações meramente de caráter matemático.

O autor relaciona então estes tipos de aproximação com as controvérsias científicas existentes na física em relação ao efeito Casimir - efeito relacionado a forças eletromagnéticas oriundas de corpos sem cargas elétricas resultantes. Segundo Reyes-Galindo, como não há experimentos de alta precisão para estudar as forças de Casimir, há uma controvérsia que há mais de meio século divide os físicos teóricos. Em outras palavras, o autor demonstra que, na impossibilidade de se obter um resultado exato, é possível chegar a diferentes resultados sobre o mesmo fenômeno, dependendo da metodologia empregada.

O capítulo 6, intitulado "Digitalizando o câncer de próstata: pensando as interseções entre engenharia e biologia na ciência contemporânea", de Marko Monteiro (Unicamp), apresenta um estudo etnográfico realizado com um grupo multidisciplinar, o qual "desenvolve um modelo computacional de transferência de calor em tecidos da próstata [que] integrará um novo tipo de protocolo cirúrgico" para este tipo de doença (p. 170). O grupo pesquisado é formado por profissionais (professores, pós-doutorandos e alunos de pós-graduação) de diferentes áreas (medicina, biologia, ciência da computação, engenharia biomédica e civil, matemática e visualização científica). Apesar de tais pesquisadores terem desenvolvido uma formação interdisciplinar, pode ser observada nas entrevistas realizadas a dificuldade encontrada por eles, em alguns momentos, para se comunicar conceitualmente.

O Capítulo 7, "Risco, perigo ou oportunidade? As disputas entre política, economia e ciência acerca dos OGMs", de Renata Campos Motta (Freire Universität Berlin), reflete sobre o modo pelo qual a política, a ciência e a economia tratam o tema do risco. Mais precisamente, o estudo tem como norte as lutas por autonomia e heteronomia travadas nestes campos em busca da definição de risco, no âmbito de uma política sanitária voltada aos alimentos geneticamente modificados. Como referencial teórico para uma análise sociológica do risco, a autora utiliza o pensamento de Ulrich Beck e de Niklas Luhmann. Assim, Motta defende que a disputa travada em torno das políticas sanitárias para os produtos transgênicos nos campos econômico, científico e político revela a ambiguidade do conceito de risco. A autora elucida essa controvérsia comparando, por exemplo, a forma antagônica como países ex- 
portadores e países importadores concebem a noção de risco: para os exportadores (como Argentina e Canadá), não há evidência de que produtos biotecnológicos causem danos à saúde diferentes daqueles causados pelos alimentos tradicionais, de modo que não há necessidade de uma política sanitária diferenciada; de modo oposto, os países importadores (as nações europeias) contra-argumentam alegando que a complexidade e os riscos em torno dos alimentos transgênicos exige a criação de políticas de regulação diferenciada.

Na continuidade, o capítulo 8 - "Os interesses heterogêneos da ciência e a politização específica da vida biológica - é assinado por Adriano Premebida (FDB). O objetivo do texto é refletir sobre o modo como a expansão das biotecnologias faz emergir "novas tendências de padrões de consumo e expectativas em saúde e formas de sociabilidade mediadas por artefatos e sistema tecnológicos" (p. 233). O autor defende que atualmente há a proliferação de produtos biotecnológicos voltados a grupos genéticos e sociais específicos. Tais produtos são produzidos através de minuciosos processos de manipulação genética realizados em laboratório e inseridos na vida cotidiana sob a forma de fármacos, hormônios, sementes etc., ante a influência da mídia, da ciência, do Estado, entre outros agentes. Estes produtos, por um lado, possibilitam às pessoas levarem uma vida mais segura e experimentarem formas inovadoras de corporalidade; por outro, cada vez mais instituem formas de governabilidade sobre a vida biológica.

O penúltimo capítulo - "Nanotecnologia nos meios de comunicação: que informação chega ao público?" - é assinado por Noela Invernizzi (UFPR) e Cibele Cavichiolo (UFPR). Segundo as autoras, a nanotecnologia é um campo científico-tecnológico emergente, o qual se legitimou rapidamente, adquirindo um papel estratégico no país, com a percepção de importantes subsídios públicos. Assim, o artigo tem o objetivo de analisar como as informações sobre esse campo chegam até o público através da mídia. Invernizzi e Cavichiolo analisam reportagens veiculadas no jornal Folha de S. Paulo, e nas revistas Veja, Época, Isto É, Galileu e Super Interessante, e, segundo as autoras, de um modo em geral, as escassas informações disponibilizadas nos veículos pesquisados retratam uma realidade de promessas otimistas relacionadas à nanotecnologia, mas que não apresentam claramente evidências factuais que sustentem tais promessas.

O último Capítulo do livro trata, na verdade, de uma entrevista realizada em 2007 com Harry Collins. Nela, Collins trata de diferentes assuntos, a exemplo de suas motivações para entrar nos estudos sociais da ciência e tecnologia, dos principais pensadores que o influenciaram, de sua relação com outros autores importantes da área, como Bloor e Knorr-Cetina etc. 
Para finalizar, Investigações contemporâneas é obra que cumpre sua promessa: apresenta ao leitor uma importante reflexão sobre o estágio atual dos estudos sociais da ciência e tecnologia. Escrito por uma equipe de autores qualificados na área, o livro apresenta discussões que abordam temas diversos, como nanotecnologia, física teórica, biotecnologia, multidisciplinaridade, risco, história dos estudos sociais da ciência e tecnologia etc.

O livro é um ótimo investimento para os pesquisadores que desejam ter um panorama teórico, metodológico e epistemológico sobre as investigações contemporâneas nos estudos sociais da ciência e tecnologia.

\section{Referências}

KUHN, Thomas. A estrutura das revoluções científicas. 4. ed. São Paulo: Perspectiva, 1996.

LYOTARD, Jean-François. O pós-moderno. 2. ed. Rio de Janeiro: José Olympio, 1986.

MERTON, Robert King. Sociologia: teoria e estrutura. São Paulo: Mestre Jou, 1970. 